\title{
OPEN
}

\section{Author Correction: Surveillance of Enterococcus spp. reveals distinct species and antimicrobial resistance diversity across a One-Health continuum}

\author{
Rahat Zaheer, Shaun R. Cook, Ruth Barbieri, Noriko Goji, Andrew Cameron, Aaron Petkau, \\ Rodrigo Ortega Polo, Lisa Tymensen, Courtney Stamm, Jiming Song, Sherry Hannon, \\ Tineke Jones, Deirdre Church, Calvin W. Booker, Kingsley Amoako, Gary Van Domselaar, \\ Ron R. Read \& Tim A. McAllister
}

Correction to: Scientific Reports https://doi.org/10.1038/s41598-020-61002-5, published online 03 March 2020

This Article contains multiple typographical errors.

In the Results section under subheading 'Sampling feedlot and downstream environment, a beef processing plant, retail meat and urban wastewater'.

"Urban wastewater contributed 31 samples in total including composite influent (post-grit tank; $\mathrm{n}=22$ ) and effluent (immediately prior to release; $n=21$ ), which were collected over the same two year period as the fecal samples."

should read:

"Urban wastewater contributed 43 samples in total including composite influent (post-grit tank; $\mathrm{n}=22$ ) and effluent (immediately prior to release; $n=21$ ), which were collected over the same two year period as the fecal samples."

In the Results section under subheading 'Enterococcus recovery',

"A total of 8,307 presumptive Enterococcus spp. isolates were recovered from all sites/sources tested including bovine feces $(n=4,499)$, feedlot catch basins $(n=510)$, surface water/natural water sources $(n=521)$, urban wastewater influent and effluent $(\mathrm{n}=222)$, beef processing (abattoir and retail beef) $(\mathrm{n}=774)$, and human clinical cases $(\mathrm{n}=1,849)$ (Fig. 1B)."

should read:

"A total of 8,375 presumptive Enterococcus spp. isolates were recovered from all sites/sources tested including bovine feces $(n=4,499)$, feedlot catch basins $(n=510)$, surface water/natural water sources $(n=521)$, urban wastewater influent and effluent $(\mathrm{n}=222)$, beef processing (abattoir and retail beef) $(\mathrm{n}=774)$, and human clinical cases $(\mathrm{n}=1,849)$ (Fig. 1B)."

"Isolate recovery rates from surface water, wastewater effluent and meat processing samples was lower for antibiotic-free as compared to non-selective media (Supplementary File 1, Table S2)." 
should read:

"Isolate recovery rates from surface water, wastewater effluent and meat processing samples was lower for antibiotic-selective as compared to non-selective media (Supplementary File 1, Table S2)."

(c) (i) Open Access This article is licensed under a Creative Commons Attribution 4.0 International License, which permits use, sharing, adaptation, distribution and reproduction in any medium or format, as long as you give appropriate credit to the original author(s) and the source, provide a link to the Creative Commons license, and indicate if changes were made. The images or other third party material in this article are included in the article's Creative Commons license, unless indicated otherwise in a credit line to the material. If material is not included in the article's Creative Commons license and your intended use is not permitted by statutory regulation or exceeds the permitted use, you will need to obtain permission directly from the copyright holder. To view a copy of this license, visit http://creativecommons.org/licenses/by/4.0/.

(C) The Author(s) 2020 